\title{
Assessing the contamination risk of five pesticides in a phreatic aquifer based on microcosm experiments and transport modelling at Sint- Jansteen (Zeeland, the Netherlands)
}

\section{Gaus ${ }^{1} \&$ K. Vande Casteele}

Laboratory for Applied Geology and Hydrogeology, University of Ghent (Belgium).

${ }^{1}$ Corresponding author, now at BRGM (French Geological Survey), 3 Avenue Claude Guillemin, BP6009, 45060 Orléans Cedex 2, France; e-mail: i.gaus@brgm.fr

Manuscript submitted: February 2003; accepted: February 2004

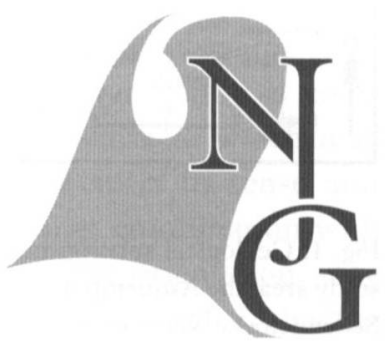

\begin{abstract}
The risk of five pesticides (atrazine, simazine, bentazone, mecoprop and MCPA) contaminating a Quaternary phreatic aquifer (the water supply area of Sint-Jansteen, the Netherlands) is assessed based on laboratory experiments and solute transport modelling (MODFLOW-MT3D). Batch experiments either show long half-lives (at least 1500 days) or no degradation at all for bentazone, atrazine and simazine while mecoprop and especially MCPA degrade much faster (half-lives down to 4.1 days). Column experiments show significant sorption to the aquifer sediment only for atrazine and simazine under certain circumstances. A series of experiments were conducted during which the type of the sediment, the grain size, the content of the organic matter and the acidity of the groundwater were varied. These experimental results were subsequently incorporated in a solute transport model for the aquifer resulting in the following ranking of the contamination risk for the selected pesticides (from low to high): MCPA, mecoprop, simazine, atrazine, bentazone. This ranking was confirmed by observed pesticide concentrations in samples taken from piezometers and extraction wells from the aquifer.
\end{abstract}

Keywords: pesticides, transport modelling, aquifer, column experiments, microcosm experiments, Zeeland.

\section{Introduction}

The contamination of shallow aquifers by agricultural byproducts (e.g. nitrate and pesticides) has become a recognized problem. While under the current legislation $0.1 \mathrm{mg} / 1$ is the limit for an individual pesticide and $0.5 \mathrm{mg} / 1$ for the pesticide load as a whole, new legislation is likely to reduce these standards further. These low limits are designed above all to indicate that their presence in groundwater is not accepted (Isenbeck-Schröter et al., 1997).

Where in the case of nitrate contamination of aquifers coherent understanding of key mechanisms is achieved using a wide variety of techniques (microcosm studies, chemical modelling, flow and transport modelling), it appears that the knowledge on pesticide behaviour on a large (aquifer) scale has not reached the same level of understanding. This is, apart from high costs involved in pesticide sampling, extraction and analysis, likely to be linked to the inherent complexity of the contamination of groundwater by pesticides caused by factors such as:

- low pesticide concentrations, close to the detection limit, causing large analytical errors and an important scatter in the analysis results;

- a large amount of different pesticides applied, with different (mostly poorly understood) chemical behaviour in the aquifer environment and unknown degradation pathways and metabolites.

Research on pesticide behaviour is therefore often focussing on experiments in a simplified environment. This can be achieved by small scale experiments with a selected sediment type, by limiting the study to a single process (e.g. sorption) or by select- 
ing one or chemically related pesticides only. Although this research is very valuable, its integration into the understanding of pesticide transport on a large, aquifer scale is not always straightforward. Where studies investigate pesticide contamination on a larger scale (e.g. aquifer or catchment scale), they are predominantly focussing on pesticide monitoring and description of the observed concentrations. Only few papers (e.g. Albrechtsen et al., 2001; Maloszewski et al., 2003) try to link the laboratory scale and the aquifer scale when looking at pesticide transport. Also modelling studies of existing pesticide contaminations in aquifers are rare (an exception is Loague et al., 1998). Indeed, factors such as uncertainties in the flow regime, boundary conditions, heterogeneity of the sediment, low sampling density and time dependency do not facilitate a full process-based interpretation.

However, from a practical point of view, a modelling approach, even when based on what might be seen as somewhat crude assumptions, can be extremely useful for the management of groundwater resources and risk assessment of groundwater contamination by pesticides. Often decisions concerning pesticide use in an area have to be taken without the large amount of information necessary for more refined modelling.

This paper describes the estimation of the contamination potential of five pesticides in a shallow porous aquifer (Sint-Jansteen, the Netherlands). This is based on experimental work (column and batch experiments) as well as solute transport modelling (MODFLOW-MT3D). The solute transport model is used as a risk assessment tool and does not intend to forecast pesticide concentrations exactly, for which parameter values as well as data availability are insufficient. The study focuses on five pesticides which are identified previously in surface and groundwater samples taken from the area: atrazine, simazine, bentazone, MCPA and mecoprop.

\section{The shallow aquifer of Sint-Jansteen}

The Quaternary phreatic aquifer at Sint-Jansteen (the Netherlands) is situated on the border between Belgium and the Netherlands (Fig. 1). It is currently used for non-drinking water supply. Several well batteries are installed in three capture areas (Wildelanden, Sint-Jansteen and Clinge). Protection zones around the wells (corresponding with the 1-year travel time zone), are installed but occasionally pesticide concentrations in the extracted water exceed the limit imposed by the European Union $(0.1 \mu \mathrm{g} / \mathrm{l})$. Principal land use in the area is maize and wheat, as well as horticulture.

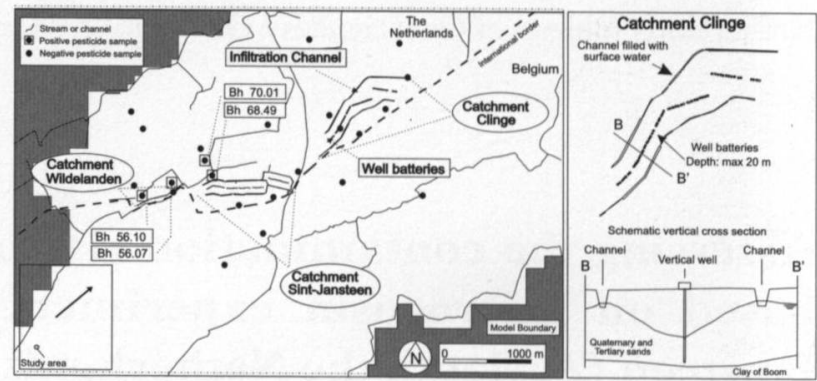

Fig. 1 Schematic representation of the water-supply area of Sint-Jansteen (Zeeland, the Netherlands) and the pesticide monitoring locations.

Geology and hydrogeology

The area is part of a polder area and different but constant water levels during wintertime and summertime are maintained by a system of locks in the streams and the dewatering channels. The extraction batteries of Clinge and Sint-Jansteen are surrounded by man made infiltration channels and are filled regularly with surface water. The wells of the water-supply area of Wildelanden are located close to one of the natural streams and passive infiltration takes place. The depth to the water table varies from less than $1 \mathrm{~m}$ in the lower lying areas to several metres in higher areas. Recharge is assumed to occur mainly in higher areas (although no direct measurements are available).

Geomorphologically the area consists of a ridge of aeolian sand deposits (De Moor \& Heyse 1978). The phreatic reservoir is limited at the base by a thick heavy clay layer $(37 \mathrm{~m}$ ) of Oligocene age (Boom Formation; Rupel Group), dipping northeasterly. The clay layer is covered in the northeastern area by glauconitic fine sand of Pliocene age. In the western part, overlying the Tertiary sequence, Quaternary fluvial deposits consisting of heterogeneous medium and fine sand with some shells of the WeichselianPleniglacial occur. The area is covered by Weichselian-Pleniglacial and Tardiglacial aeolian well sorted fine sands. The aeolian sands are separated by a thin peat layer, probably of Alleröd age. This layer is not identified in all borings, if present, its thickness ranges from 0 to $0.4 \mathrm{~m}$.

The flow regime modelled using MODFLOW (Mc Donald \& Harbaugh, 1988) is described in detail in Gaus (2000). The modelled head distribution at the base of the aquifer is shown in Fig. 2. The natural groundwater heads are determined mainly by the presence of the ridge of aeolian sand deposits. Heads are high in elevated areas and decrease towards lower lying areas. Vertical head differences are in the order of centimetres across the peat layer. However, close to the well batteries important cones of depression are 


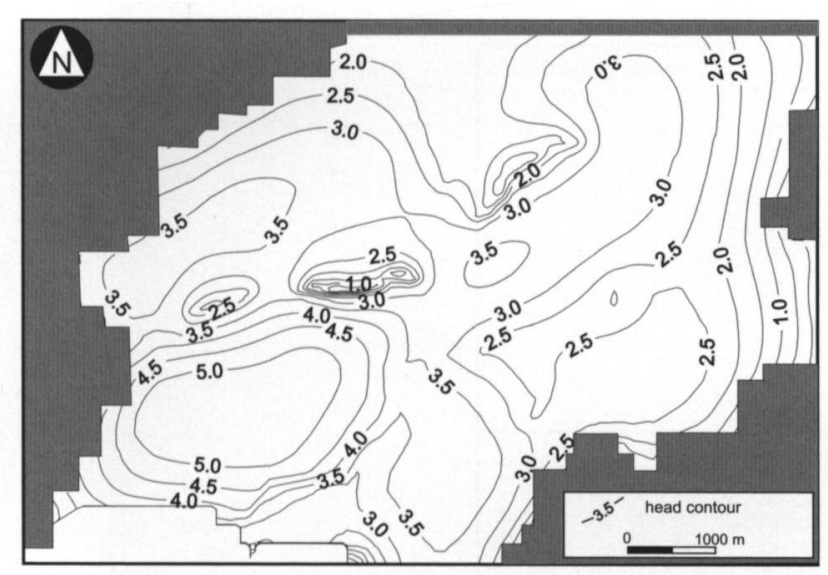

Fig 2 Calculated hydraulic heads based on the flow model described in Gaus (2000) in the middle of the aquifer showing the depression cones of the three catchment areas (Sint-Jansteen, Clinge and Wildelanden)

present and large hydraulic gradients induce strong vertical flow, leading to short residence of water infiltrating in the aquifer close to the wells.

\section{Pesticide concentrations}

The selected pesticides are monitored both in the extracted water from the well batteries at each extraction site (Clinge, Sint-Jansteen, and Wildelanden) as well as in 25 observation boreholes within the area. Sampling sites are shown in Fig. 1, and results are given in Table 1.

Water samples from the extraction wells in the three areas were taken regularly in 1992, with a maximum of 4 samples per area. Analysis results of the 12 samples show significant contamination with bentazone (up to $0.29 \mu \mathrm{g} / \mathrm{L} ; 9$ out of 12 samples), atrazine (up to $0.06 \mu \mathrm{g} / \mathrm{L} ; 5$ out of 12 samples), and occasionally mecoprop (up to $0.09 \mu \mathrm{g} / \mathrm{L} ; 2$ out of 12 samples) in the water-supply areas of Sint-Jansteen and Wildelanden. The detection limits of the analysis vary per sample due to differences in their organic contents, which distort the baseline during the chromatographic analysis. In the extracted water from the Clinge area only bentazone is observed in 1 sample. This is possibly a consequence of the Clinge capture area being mainly covered with woods, where no pesticide applications occur. Both simazine and MCPA are not detected in the water of the well batteries.

Monitoring of the observation boreholes took place during 1992-95; 48 samples were taken. Only occasionally contamination has been measured. Positive samples contained bentazone ( 5 samples; as much as $0.16 \mu \mathrm{g} / \mathrm{L}$ ), mecoprop (2 samples; up to $0.65 \mu \mathrm{g} / \mathrm{L}$ ), simazine ( 1 sample, $0.03 \mu \mathrm{g} / \mathrm{L}$ ) and atrazine ( $1 \mathrm{sam}$ ple; $0.16 \mu \mathrm{g} / \mathrm{L})$. MCPA was not detected in any of the observation boreholes.
Results indicate that the extracted water of two of three water-supply areas (Wildelanden and SintJansteen) is contaminated, whereas the wider area around the wells is in general free of pesticides.

\section{Experimental part}

Laboratory experiments were undertaken in order to estimate degradation and sorption parameters of the selected pesticides and their sensitivities. These were subsequently fed in a solute transport model (described in the next section). Batch experiments were carried out to study degradation behaviour. Degradation is defined as the rate at which the original compound disappears. Sorption was studied by column experiments and quantified by measuring the retardation factor of the pesticides with respect to a conservative tracer.

\section{Materials and Sediment Samples}

Pesticide standards (Pestanal) were obtained from Riedel - De Haën (Seelze, Germany). For the column experiments chloride ( $\mathrm{KCl}, 1000 \mathrm{ppm})$, as a conservative tracer, is used.

Quaternary samples were taken at a depth of 2 to 5 $\mathrm{m}$. They contained $98.70 \%$ of sand, $1.25 \%$ of clay and silt and $0.05 \%$ of organic matter and had an ion exchange capacity of $0.82 \mathrm{meq} / 100 \mathrm{~g}$. Tertiary samples were taken at a depth of 14 to $15 \mathrm{~m}$ and contained $96.85 \%$ of sand, $3.14 \%$ of clay and silt, $0.10 \%$ of organic matter and have an ion exchange capacity of $5.82 \mathrm{meq} / 100 \mathrm{~g}$. The tertiary sediment is also high in the iron-oxide mineral celadonite (up to $15 \%$ ). The sediment samples were stored under water saturated conditions and kept in the dark at $11^{\circ} \mathrm{C}$.

Artificial groundwater with the same composition as the groundwater at the test site has been composed using commercial salts and acids. This reduced interference by dissolved organic matter (generally present in natural groundwater) during the chromatographical analysis. The artificial groundwater had the following composition: $1.07 \mathrm{mmol} / 1 \mathrm{Na}^{+}, 0.12 \mathrm{mmol} / \mathrm{l}$ $\mathrm{K}^{+}, 3.79 \mathrm{mmol} / 1 \mathrm{Ca}^{2+}, 0.38 \mathrm{mmol} / 1 \mathrm{Mg}^{2+}, 2.17$ $\mathrm{mmol} / 1 \mathrm{Cl}{ }^{-}, 2.31 \mathrm{mmol} / 1 \mathrm{SO}_{4}{ }^{2-}$ and $2.72 \mathrm{mmol} / 1$ $\mathrm{HCO}_{3}{ }^{-}$.

\section{Degradation experiments}

A cocktail of the 5 pesticides was added to 0.51 glass bottles filled with an equilibrated mixture of $375 \mathrm{ml}$ of artificial groundwater and $75 \mathrm{~g}$ of sediment. Relatively high initial pesticide concentrations between 90 and $400 \mu \mathrm{g} / \mathrm{l}$ were chosen to allow for the quantifica- 


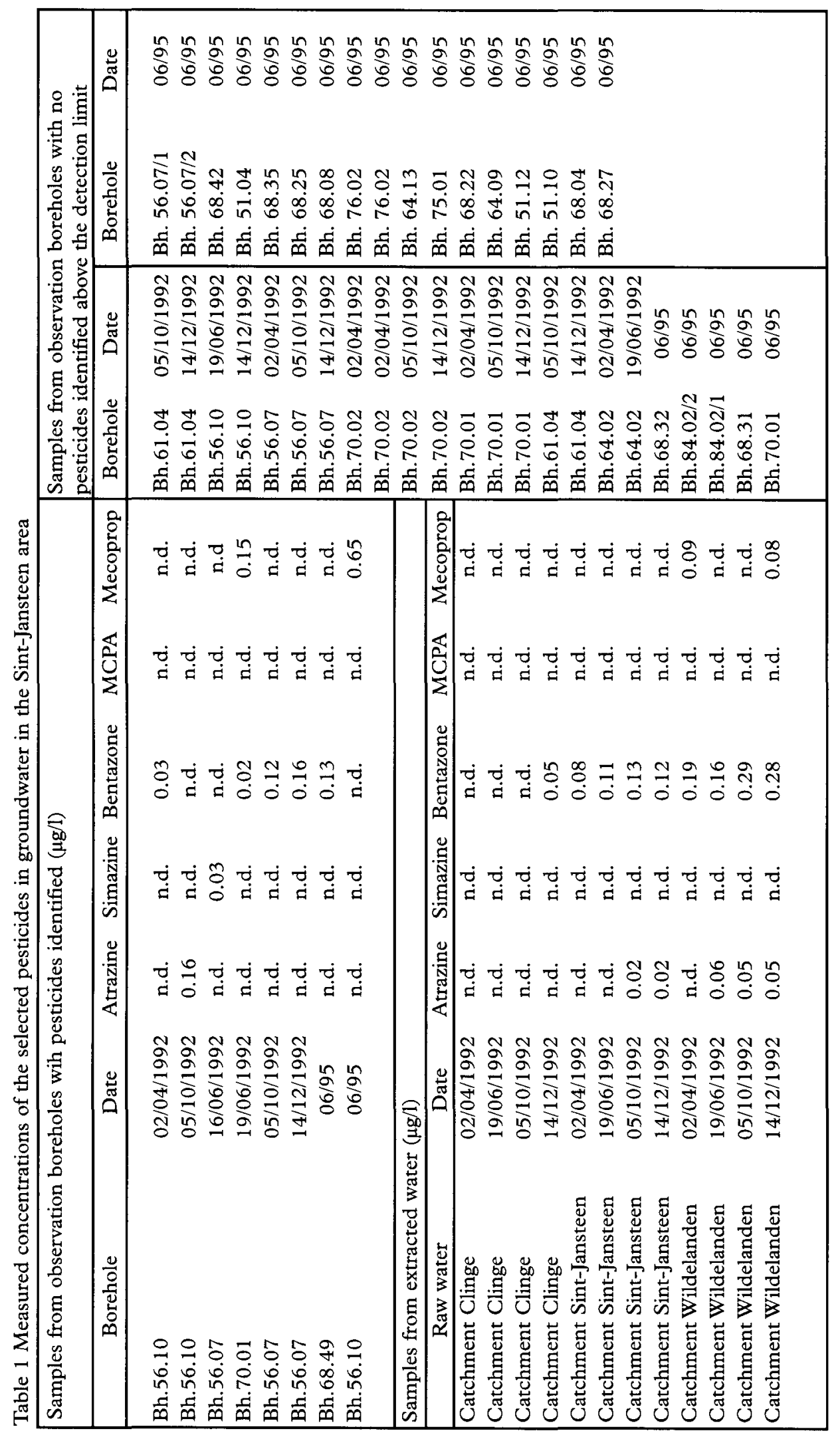


tion of the half-lives because of two reasons: a) halflives under these particular conditions were not known at the start of the experiments, b) since all fives pesticides were measured simultaneously in the same sample and the total number of samples which can be taken during an experiment is limited, one has to assure that measured concentrations for all pesticides are exceeding the detection limit (influenced by the matrix in the sample) in a sufficient number of samples to allow for the calculation of the half-life. The batches were kept in the dark at $11^{\circ} \mathrm{C}$ and samples $(25 \mathrm{ml})$ were taken at logarithmically increasing time intervals for at least 194 days up to 385 days. Each experiment was carried out in triple and mean values were used; blank experiments (batches without sediment) were used as control. Degradations (halflives) were quantified by fitting a first order kinetics function to the measured concentrations. Time 0 concentrations were omitted in order to avoid that sorption of pesticides onto the sediment would disturb the calculations. This assumes however that the sorption equilibrium is established reasonably fast (before the following sample was taken). The $90 \%$-confidence intervals for the calculated half-lives were estimated as described in Draper \& Smith (1981). Confidence intervals were not calculated for some measurements of fast degrading pesticides for which the number of observations was to little.

\section{Sorption experiments}

Artificial groundwater from a reservoir was pumped upwards (flow rate: $10-12 \mathrm{ml} / \mathrm{h}$ to represent slow groundwater flow) with a peristaltic pump into a glass column (length $90 \mathrm{~cm}$, diameter $2.5 \mathrm{~cm}$ ). This column was filled with the sediment kept in the dark at $11^{\circ} \mathrm{C}$. Before the column inlet, a cocktail of pesticides (between 20 and $80 \mu \mathrm{g}$ depending on the pesticide type in $1.8 \mathrm{ml}$ water) and potassium chloride, as a conservative tracer (chloride) were injected. The outlet of the column is connected to a fraction collector. Each $20 \mathrm{ml}$ fraction of column effluent was collected and analysed (up to 2 to 4 pore volumes depending on the experiment). Breakthrough curves were plotted and recoveries of the tracer and the pesticides calculated. The retardation factor $(R)$ indicating the retardation of the pesticides with respect to the tracer was calculated using the breakthrough curves as described in Matthess (1994). Also the total amount of pesticides recovered during each experiment was calculated (indicated as $\mathrm{R} \%$ ). Degradation of the pesticides during the sorption experiment was assumed not to be substantial for bentazone, atrazine, simazine and mecoprop because of the short duration of the experiments in comparison to the much longer degradation half-lives. In the case of MCPA however, degradation could not be excluded under certain circumstances. No correction was executed, however. No replications of the column experiments are executed because of budget constraints. The accuracy of the calculated retardations is estimated to be around 0.05 .

\section{Sensitivity analysis}

The influence of some sediment and groundwater characteristics on the sorption and degradation of the selected pesticides was evaluated in a sensitivity analysis. The parameters tested were: the composition of the sediment (grain size and organic content), the type of the sediment (Tertiary and Quaternary sands) and the acidity of the groundwater $(\mathrm{pH})$ in contact with the sediment. The influence of organic matter content was evaluated by comparing results before and after removing the organic material from the sediment by adding $\mathrm{H}_{2} \mathrm{O}_{2}$ and heating the sediment sample; this treatment also eliminated all microbial activity and therefore strictly spoken no distinction can be made between the pure influence of the presence of organic matter and that of microbial activity. The influence of the clay and silt fraction was determined by comparing results before and after removing the fraction $<50 \mu \mathrm{m}$ (clay and silt fraction) by wet sieving. The type of the sediment was evaluated by comparing the results of the experiments on the Quaternary sediment with these on the Tertiary sediment. Due to filtration difficulties, as a result of the higher clay content in the Tertiary sediment, no batch results were reported for this sediment. The acidities of the groundwater tested were $\mathrm{pH} 8.3$ (both batch and column), $\mathrm{pH} 7.5$ (batch) or $\mathrm{pH} 7.8$ (column) and $\mathrm{pH}$ 6.7 (both batch and column). The experiments with $\mathrm{pH}$ conditioning required a treatment of the sediment with a $\mathrm{Na}_{3} \mathrm{PO}_{4} / \mathrm{H}_{3} \mathrm{PO}_{4}$ buffer $(0.2 \mathrm{M}, \mathrm{pH}$ adjusted) to maintain a constant $\mathrm{pH}$ for the total length of the experiment. Once the $\mathrm{pH}$ was established the sediment is rinsed with $\mathrm{pH}$ adjusted artificial groundwater (also adjusted with $\mathrm{H}_{3} \mathrm{PO}_{4}$ ).

\section{Measurement and analysis}

Samples from the batch experiments were filtered to eliminate sediment particles (glass filter: $0.3 \mu \mathrm{m}$ ). For the extraction and the analysis the method described in Vande Casteele et al. (2000) was applied. This method, a combination of solid phase and liquid-liquid extraction and subsequent HPLC analysis, allowed for the analysis of the 5 pesticides in one run 
with high accuracy. Also two metabolites of atrazine (desethylatrazine and desisopropylatrazine) were quantified using this method. Chloride samples are analysed with the Cotlove-Buchler-chloridometer.

\section{Results}

Results of the degradation and sorption experiments are shown in Table 2 and 3 respectively.

\section{Degradation}

During the experiment using the untreated Quaternary sediment (experiment D1) degradation of all the pesticides is observed. Half-lives are large for the $s$-triazines (simazine: $1800 \mathrm{~d}$ and atrazine: $2200 \mathrm{~d}$ ) and bentazone $(1500 \mathrm{~d})$. The phenoxy acids show a lower persistence (MCPA: $4.1 \mathrm{~d}$ and mecoprop: $280 \mathrm{~d}$ ). In the case of MCPA, a lag period was observed before degradation takes place. When the organic carbon and the microbial activity are eliminated in the sedi-

Table 2 Experimental degradation half-lives determined for the selected pesticides using batch experiments thereby assuming first order rate degradation as well as their $90 \%$ confidence intervals (where estimation was possible).

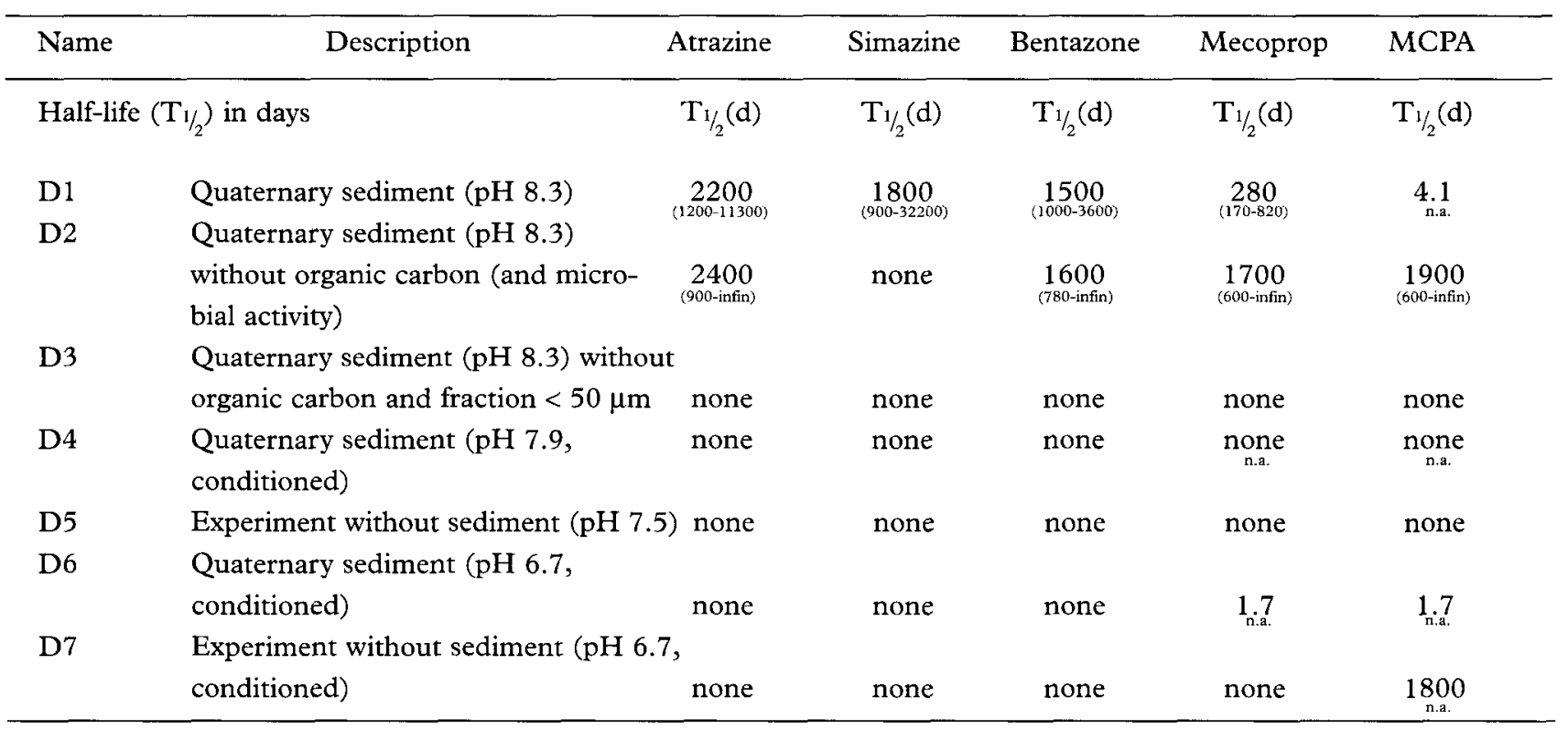

Table 3 Experimental sorption rates determined using column experiments for the five pesticides (assuming a linear sorption isotherm).

\begin{tabular}{|c|c|c|c|c|c|c|c|c|c|c|c|}
\hline \multirow{2}{*}{$\begin{array}{l}\text { Name } \\
\text { Retard }\end{array}$} & \multirow{2}{*}{$(\mathrm{R})$} & \multicolumn{2}{|c|}{ Atrazine } & \multicolumn{2}{|c|}{ Simazine } & \multicolumn{2}{|c|}{ Bentazone } & \multicolumn{2}{|c|}{ Mecoprop } & \multicolumn{2}{|c|}{ MCPA } \\
\hline & & $\mathbf{R}$ & $\mathrm{R} \%$ & $\mathrm{R}$ & $\mathrm{R} \%$ & $\mathrm{R}$ & $\mathrm{R} \%$ & $\mathrm{R}$ & $\mathrm{R} \%$ & $\mathbf{R}$ & $\mathrm{R} \%$ \\
\hline \multicolumn{12}{|c|}{ Recuperation (R\%) } \\
\hline \multirow[t]{2}{*}{$\mathrm{S} 1$} & Quaternary sediment $(\mathrm{pH}$ & & & & & & & & & & \\
\hline & 8.3) & 1.07 & 77 & 1.14 & 67 & 0.98 & 102 & 0.98 & 106 & 1.00 & 104 \\
\hline \multirow[t]{2}{*}{$\mathrm{S} 2$} & Quaternary sediment & & & & & & & & & & \\
\hline & $\begin{array}{l}\text { (pH 8.3) without organic } \\
\text { carbon }\end{array}$ & 1.03 & 88 & 1.10 & 74 & 1.02 & 102 & 1.02 & 108 & 0.99 & 86 \\
\hline \multirow[t]{2}{*}{ S3 } & Quaternary sediment ( $\mathrm{pH}$ & & & & & & & & & & \\
\hline & $\begin{array}{l}\text { 8.3) without organic carbon } \\
\text { and fraction }<50 \mu \mathrm{m}\end{array}$ & 1.04 & 99 & 1.11 & 88 & 0.97 & 98 & 1.02 & 108 & 0.99 & 92 \\
\hline $\mathrm{S} 4$ & $\begin{array}{l}\text { Quaternary sediment }(\mathrm{pH} \\
7.4, \text { conditioned) }\end{array}$ & 1.16 & 92 & 1.31 & 81 & 1.00 & 83 & 1.00 & 65 & 1.01 & 67 \\
\hline S5 & $\begin{array}{l}\text { Quaternary sediment }(\mathrm{pH} \\
6.7, \text { conditioned) }\end{array}$ & 1.10 & 99 & 1.28 & 81 & 0.98 & 84 & 0.98 & 81 & 0.99 & 68 \\
\hline S6 & Tertiary sediment ( $\mathrm{pH} 7.7)$ & 1.92 & 81 & $>5.4$ & - & 0.96 & 77 & 1.01 & 78 & 1.05 & 83 \\
\hline
\end{tabular}


ment (D2), an increase of the half-lives is measured. This is most obvious for the phenoxy acids (half-lives up to $1700 \mathrm{~d}$ (mecoprop) and $1900 \mathrm{~d}$ (MCPA)). In the case where the sediment is depleted of organic carbon, microbial activity and both the clay and silt fraction (experiment D3) no degradation of any of the pesticides can be observed. Lowering the groundwater $\mathrm{pH}$ (experiments D4 and D6) leads to full persistence of the $s$-triazines and bentazone during the experiment but increases the degradation rate of the phenoxy acids dramatically. At $\mathrm{pH} 6.7$ half-lives are reduced to $1.7 \mathrm{~d}$ for both MCPA and mecoprop. In the experiments without sediment (experiments D5 and D7) no degradation is observed, except for the pH-conditioned experiment where MCPA slowly degrades (half-life $1800 \mathrm{~d}$ ). An example of the degradation experiments is shown in Fig. 3 (upper).

One has to take into account that, because of the
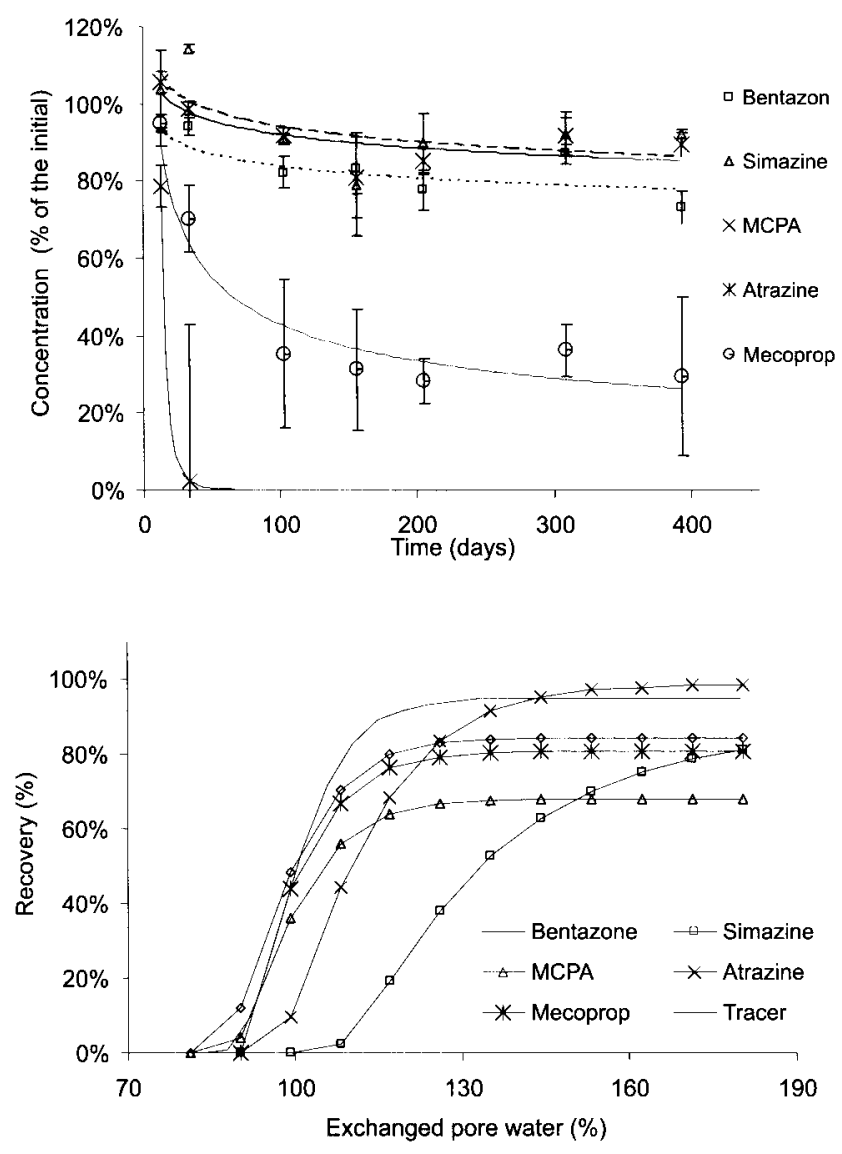

Fig. 3 Examples of experimental results on the microcosm experiments (upper: experiment D1 see Table 2) and the column experiments (lower: experiment S4 see Table 3).

very slow degradation rate of some of the pesticides in some experiments, large extrapolations are made to calculate the half-lives. These calculated half-lives, exceeding the total length of the experiment (maximum 385 days), are therefore less accurate (as also indicated by their large confidence intervals).

\section{Sorption}

In the experiment using the untreated sediment (experiment $\mathrm{S} 1$ ) the $s$-triazines are slightly retarded (retardation 1.06 and 1.14). Bentazone, as well as the phenoxy acids do not show any retardation. When the organic content is eliminated (experiment S2) retardation slightly reduces for the $s$-triazines (retardation 1.03 and 1.10). Other pesticides are not influenced. Elimination of the organic fraction and the clay and silt (experiment S3) has no further significant influence on the retardation factors. Lowering the groundwater $\mathrm{pH}$ (experiment $\mathrm{S} 4$ and $\mathrm{S} 5$ ) induces a small non linear increase in retardation for the $s$-triazines. For the phenoxy acids and bentazone, no retardation is observed. Comparing the Tertiary sediment (S6) retardations with the Quaternary sediment (S1-S5) retardations, a large increase is observed for the $s$-triazines (retardation 1.92 and $>5.4$ ). Again, for the phenoxy acids and bentazone there is no influence on retardation. An example of the column experiments is shown in Figure 3 (lower).

\section{Discussion}

Atrazine and simazine - The two s-triazines are fairly resistant under the measured circumstances. Either they do not degrade at all or their half-lives are very large under measured aquifer conditions. Degradation of atrazine in soils is studied by numerous authors (Agertved et al., 1992; Li et al., 1996; Beck \& Jones, 1996) and is microbiologically triggered. However, at greater depths persistence increases as described by Fomsgaard (1995) for the subsoil and by Klint et al. (1993) for certain aquifer environments, which can possibly attributed to lower microbial activities with increasing depths. Table 3 shows that sorption seems to be relatively insignificant under most circumstances. These findings are consistent with Pestemer \& Nordmeyer (1990) reporting retardations between 1.12 and 1.20 for atrazine. The increased sorption on the Tertiary sediment might be caused by the high iron content in the sediment $(15 \%)$. Several authors point at the importance of sorption of pesticides on iron-oxides (Adams, 1973; Moreau-Kervévan \& Mouvet, 1998).

Bentazone - Also bentazone is highly recalcitrant under the measured aquifer conditions. Degradation does not take place or is extremely slow. This seems opposite to its behaviour in soil where it degrades fast ( 2 to 15 weeks) (Gaston et al., 1996) and the unsaturated zone (Mouvet et al., 1997) where also fast degradation is observed. But also Albrechtsen et al. (2001) observed high persistence of bentazone in 
aquifer environments. Since it is likely to be present in its ionic form (due to its acidic character) at normal groundwater $\mathrm{pH}$-values it is highly soluble. This is illustrated here by the fact that no sorption on the sediment could be measured in any of the tested circumstances.

MCPA and Mecoprop - The tested phenoxy-acids behave in a different way in an aquifer environment than the three previous pesticides. Also these pesticides are acidic (as is the case with bentazone) and are therefore highly soluble in water under the measured circumstances, therefore showing no sorption to the sediment. However, they are far less resistant and degradation is completed in a few days under certain circumstances. This is the case especially in an almost neutral $\mathrm{pH}$-environment ( $\mathrm{pH}$ 6.7). The degradation of many phenoxy acids is, according to several authors (Lappin et al., 1985; Helweg, 1993; Smith \& Hayden, 1981), driven by microbial activity. This is also confirmed in these experiments in that a lag period before the start of the degradation is observed and that the elimination of microbial activity increases the half-lives substantially. The presence of this lag-period is a typical sign of microbial degradation, since microbial populations first have to build up before degradation starts. In the absence of microbial activity also these pesticides might become recalcitrant.

It cannot be excluded that high initial concentrations during the degradation experiments accelerate the degradation and that half-lives calculated for fast degrading pesticides are shorter than one would expect in a low concentration environment as described in Thorang et al. (2003). However, differences in degradation rates between fast degrading and slowly degrading pesticides are orders of magnitudes and model results based on the experimental results are used for comparison of the behaviour of pesticides only and do not intend to forecast exact concentrations. It was felt that the quantification of all five pesticides in the same sample from the same experiment, thereby excluding experimental variability, is the best guarantee for this comparison although this implies the use of high initial concentrations in the experiments.

\section{Assessing the contamination potential of base- don solute transport modelling}

A solute transport model, in which the experimental findings can be incorporated, is developed. The transport model is based on the flow model for the aquifer described in Gaus (2000) and is used as a risk assessment tool to estimate the contamination potential of the selected pesticides based on their degradation and sorption characteristics. The value added by combination of the experimental data and the model is that the determined parameters are coupled to the complex velocity field of the groundwater flow in the area resulting in zones around the extraction wells where potential contamination of groundwater can occur. To achieve this, a simple pesticide application scheme is assumed and an estimation of the fraction of the applied pesticides reaching the saturated zone of the aquifer is derived from the literature. The results are subsequently compared qualitatively with the observed pesticide contamination in the aquifer.

\section{Governing equations}

The transport of the pesticides is modelled using the MT3D-code (Zheng, 1990). Transport in the saturated zone is modelled taking into account first order degradation and equilibrium linear sorption:

$$
\begin{gathered}
R \frac{\partial C}{\partial_{t}}=\frac{\partial}{\partial x_{i}}\left(D_{i j} \frac{\partial C}{\partial x_{j}}\right)-\frac{\partial}{\partial x_{i}}\left(v_{i} C\right)+\frac{q^{e}}{n_{e}} C_{e x}- \\
\frac{\rho_{b}}{n_{e}} \frac{\partial C_{s}}{\partial t}-\lambda\left(C+\frac{\rho_{b}}{n_{e}} C_{s}\right)
\end{gathered}
$$

where $x_{i}$ is the distance along the representative Cartesian coordinate axis; $D_{i j}$ is the coefficient for the hydrodynamic dispersion tensor; $C$ is the concentration of the solute dissolved in the saturated subsurface; $v_{i}$ is the average linear pore-water velocity vector; $q_{s}$ is the volumetric flux of water per unit volume of saturated porous media; $n_{e}$ is the effective porosity of the porous medium; $r_{b}$ is the bulk density of the porous medium; $C_{e x}$ is the concentration of the solute in the sources/sinks, $l$ is the rate constant of the firstorder degradations; $C_{s}$ is the concentration of the solute absorbed on the porous medium and $t$ is time.

The transport equation is coupled to the flow equation by the flow velocity:

$v_{i}=-\frac{K_{i i}}{n_{e}} \frac{\partial h}{\partial x_{i}}$

where $K_{i i}$ is a principal component of the hydraulic conductivity tensor and $h$ is the hydraulic head.

\section{Modelling specifications and scenario}

Since only fragmented data on pesticide use in the area are available, to be able to assess the contamination risk of the pesticides, it is assumed that the 5 selected pesticides are applied over the whole of the area for a consecutive period of 20 years. 
Table 4 Specifications of the processes incorporated in the solute transport model used to assess the contamination potential of the selected pesticides.

Solute transport model specifications

Sorption

Retardation factors (Eq.(1)); R values were taken from Table 3 (S1 and S6) for each pesticide. Based on the

Henry sorption isotherm $R=1+\left(\rho_{b} / n\right) K_{D}$, an assumed bulk density $\left(\rho_{b}\right)$ of $1708 \mathrm{~kg} \mathrm{~m}^{-3}$ and an assumed porosity

(n) of 0.2 , the sorption coefficient was calculated using the retardation factor

Degradation

First order rate degradation (Eq.(1)): $\lambda=\ln 2 / T_{1 / 2}$, half-lifes $\left(T_{1 / 2}\right)$ for the 5 pesticides were taken from Table 2 (D1)

Dispersion

Hydrodynamic dispersion (Eq. (1)); $D_{i j}=\alpha v+D^{*}, \alpha$ is the dispersivity, $v$ is the pore water velocity, and $D^{*}$ is the coeficient of the molecular diffusion. Using Gelhar et al. (1992) (experimental field and laboratory results) and Lebbe (1996) (inverse modeling result for coastal aquifers in Belgium) a longitudinal dispersivity $\left(\alpha_{\mathrm{L}}\right)$ of $0.1 \mathrm{~m}$, a transversal horizonal dispersivity $\left(\alpha_{\mathrm{TH}}\right)$ of 0.0001 and a transversal vertical dispersivity of 0.00001 were assumed.

Pesticide input parameters

A constant pesticide concentration was defined in the effective recharge of the model for the 5 selected pesticides. These values were estimated based on existing literature and calculated as described in the text. The amount of pesticides in drainage and infiltration canals was estimated as $0.02 \mu \mathrm{g} / \mathrm{l}$, being an overall mean concentration (based on surface water analysis).

Calculation parameters

For the calculation the hybrid method of characteristics (HMOC, Zheng (1990) was considered the most appropriate for this case characterised by sharp concentration fronts.

The pesticide influx from the unsaturated zone (as part of the effective recharge) is estimated based on Van der Linden \& Boesten (1989) who calculated the risk for each pesticide leaching to the groundwater. Van den Berg et al. (1990) used these calculations to link land use and pesticide concentration seeping to the saturated zone taking into account their recommended application quantities. For more detail reference is made to these two publications. Based on these results and agricultural land use data for the area of Sint-Jansteen it is assumed that as a yearly average the following pesticide concentrations are present in the effective recharge of the aquifer: bentazone: $28.8 \mu \mathrm{g} / 1$; atrazine: $0.15 \mu \mathrm{g} / 1$; simazine: $0.23 \mu \mathrm{g} / \mathrm{l}$; mecoprop: $2.70 \mu \mathrm{g} / \mathrm{l}$; MCPA: $0.02 \mu \mathrm{g} / 1$.

The specifications for the transport model are listed in Table 4. A thorough sensitivity analysis has been carried out (Gaus, 1998). This showed that the influx from the unsaturated zone and the degradation halflives of the pesticides are the most sensitive parameters, therefore having the highest impact on the contamination potential of the pesticides.

\section{Results and comparison with measured concentrations}

The modelled concentrations for each of the selected pesticides after 20 years of pesticide application in the model layer wherein the wells are located are shown in Fig. 4. For bentazone a high contamination poten- tial can be observed in large parts of the aquifer, especially in high recharge areas. The reason for this high contamination potential is a high influx of bentazone from the unsaturated zone and a high persistence of bentazone in the saturated zone. This high contamination potential is confirmed by the large amount of groundwater samples contaminated with bentazone. It is detected frequently in the extracted water, but also in the observation wells in the area (see Table 1). However, it is clear that the actual modelled concentrations by no means represent the actual situation since modelled calculations are far higher than observed ones. This is a consequence of the assumptions made when setting up the model whereby it was assumed that all pesticides were applied over the whole area during 20 years. This was definitely not the case, but more accurate estimations could not be made due to the lack of data on actual pesticide applications. However, although the modelled concentrations are far higher than the observed ones, the model results clearly indicate that this pesticide poses a high risk when applied intensively in the area.

The other pesticides appear to be far less contaminating, modelled concentrations are around 150 times lower than in the case of bentazone. The modelling results for both the s-triazines (atrazine \& simazine) show a very similar pattern, the slightly longer half-life of atrazine in the saturated zone is apparently compensated by its lower influx from the un- 

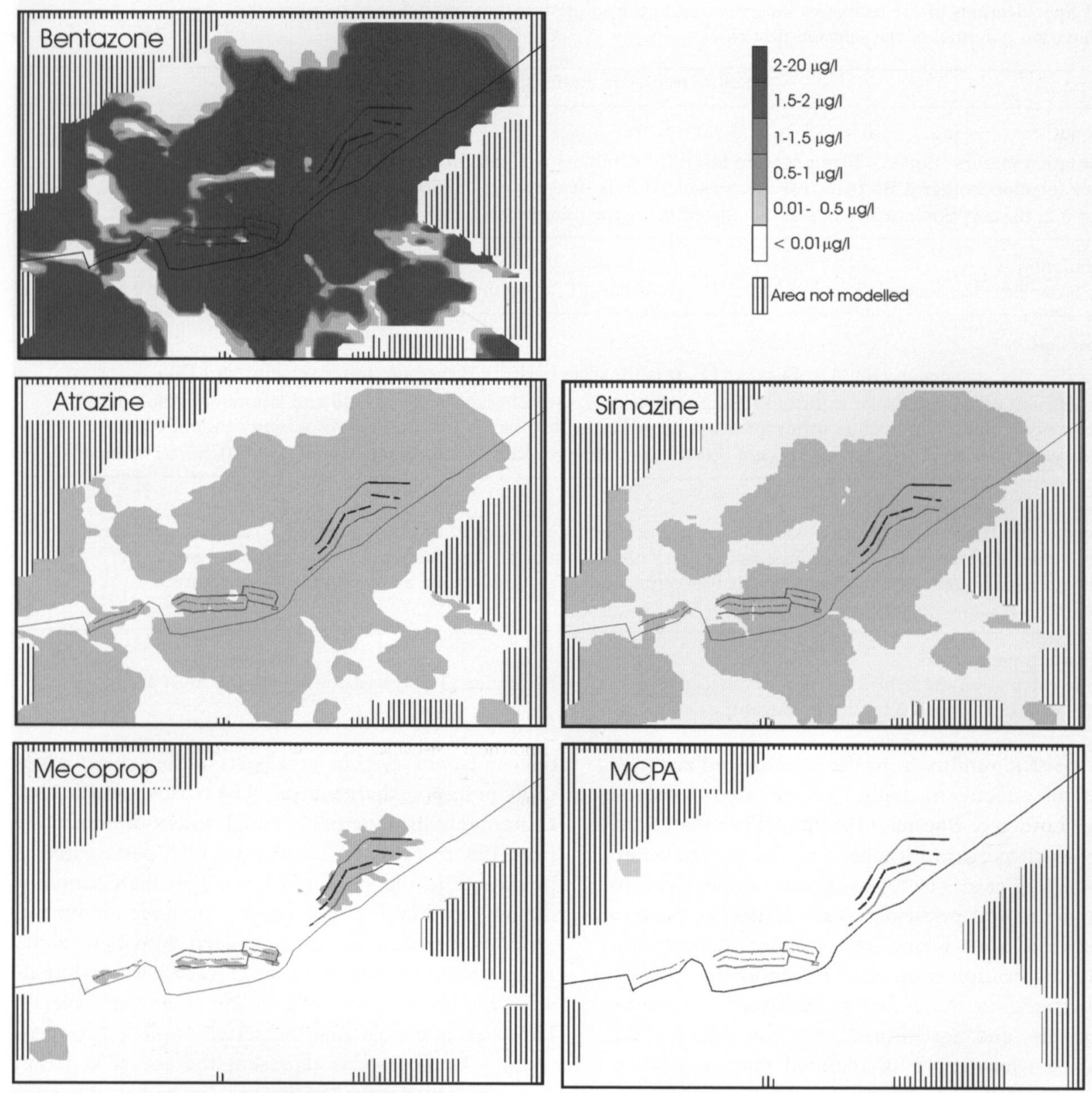

Fig. 4 Potential pesticide contamination in the Sint-Jansteen area at a depth of $15-20 \mathrm{~m}$ in case the selected pesticides were applied over the whole area for 20 consecutive years.

saturated zone. For atrazine the modelled contamination potential is in agreement with the field measurements since it is detected several times in the extracted water as well as in one observation well. Simazine, on the other hand, is only measured in one observation well. The reason for the more frequent occurrence of atrazine compared to simazine is unclear, an explanantion might be that the latter is less frequently used than the first.

The contamination pattern for the phenoxy acids seems to be completely determined by their short half-lives. Mecoprop concentrations are only modelled in the upper part of the aquifer (not shown) and deeper down near the extraction wells where residence times are short and vertical flow rates are high.
Mecoprop has been detected twice in the extracted water and once in an observation well, which is considerably less than atrazine and much less than bentazone. For MCPA, due to its very fast degradation rates, no contamination of the saturated zone is modelled. It has not been observed in any of the groundwater samples either, although its presence in river water samples might indicate that MCPA has been used in the area.

\section{Summary and conclusions}

An assessment of the contamination potential on an aquifer scale (Sint-Jansteen, the Netherlands) of 5 pesticides (atrazine, simazine, bentazone, MCPA and 
mecoprop) is carried out using experimental results and solute transport modelling. The experimental work, focussing on degradation and sorption behaviour, highlights the recalcitrant behaviour of both the s-triazines atrazine and simazine as well as bentazone. Significant sorption to the sediment can only be observed for the s-triazines (atrazine and simazine). Solute transport modelling is applied and although there are severe information shortages (e.g. pesticide use and application frequency), which does not allow accurate modelling to be executed, it is possible to rank the selected pesticides from highly contaminating to less contaminating under the given complex flow and extraction regime. This ranking is, in order of increasing contamination potential, MCPA, mecoprop, simazine, atrazine and bentazone and proves to be in good agreement with the observed pesticide concentrations in groundwater samples from the area and from extracted water for water supply. This illustrates that a combination of experimental work and solute transport modelling can be a useful tool in managing groundwater resources in areas where agricultural use and groundwater extraction are interfering.

\section{Acknowledgements}

The authors are grateful to their colleagues at the LTGH (University of Ghent, Belgium) for their contributions during discussions and would like to thank J. Bloomfield (British Geological Survey, UK) for his suggestions. This research was financed by the University of Ghent (Belgium) and the Fund for Scientific Research (Flanders, Belgium) while NV Deltan (The Netherlands) provided part of the field measurements.

\section{References}

Adams, R.S., 1973. Factors influencing soil adsorption and bioactivity of pesticides. Residue Reviews 47: 1-54.

Agertved, J., Rügge, R. \& Barker J.F., 1992. Transformation of the pesticides MCPP \& atrazine under aquifer conditions. Ground Water 30: 500-506.

Albrechtsen, H.J., Mills, M.S., Aamand, J. \& Bjerg, P.L., 2001. Degradation of herbicides in shallow Danish aquifers: an integrated laboratory and field study. Pesticide Management Science 57:341-350.

Beck, A.J. \& Jones, K.C., 1996. The effects of particle-size, organicmatter content, crop residues and dissolved organic-matter on the sorption kinetics of atrazine and isoproturon by clay soil. Chemosphere 32: 2345-2358.

De Moor, G. \& Heyse, I., 1978. De morfologische evolutie van de Vlaamse Vailei. De Aardrijkskunde 4: 343-375.

Draper, N. \& Smith, H., 1981. Applied regression analysis - Second edition. John Wiley \& Sons (New York): 709 pp.

Fomsgaard, I.S., 1995. Degradation of pesticides in subsurface soils, unsaturated zone - a review of methods and results. International Journal of Environmental Analytical Chemistry 58: 231-245.

Gaston, L.A., Locke, M.A. \& Zablotowicz, R.M., 1996. Sorption and degradation of bentazon in conventional- and no-till dundee soil. Journal of Environmental Quality 25:120-126.

Gaus, I., 1998. Hydrogeologische en hydrochemische aspecten van de verspreiding van pesticiden in het grondwater, case: het waterwingebied van Sint-Jansteen (Nederland). University of Ghent (Belgium): unpublished Ph.D-thesis: $330 \mathrm{pp}$.

Gaus, I., 2000. Effects of water extraction in a vulnerable phreatic aquifer: consequences for groundwater contamination by pesticides, Sint-Jansteen area, the Netherlands. Hydrogeology Journal 8: 218-229.

Gelhar, L.W., Welty, C. \& Rehfeldt, K.R., 1992. A critical review of data on field-scale dispersion in aquifers. Water Resources Research 28: 1955-1974.

Helweg, A., 1993. Degradation and adsorption of ${ }^{14} \mathrm{C}$-mecoprop (MCPP) in surface soils and in subsoil. Influence of temperature, moisture content, sterilization and concentration on degradation. Science of the Total Environment 132: 229-241.

Isenbeck-Schröter, M., Bedbur, E., Kofod, M., König, B., Schramm, T. \& Matthess, G., 1997. Occurrence of pesticide residues in water - assessment of the current situation in selected EU countries. Berichte, Fachbereich Geowissenschaften, Universität Bremen 91: 1-65.

Klint, M., Arvin, E. \& Jensen, B.K., 1993. Degradation of the pesticides mecoprop and atrazine in unpolluted sandy aquifers. Journal of Environmental Quality 22: 262-266.

Lebbe, L., 1996. Regression modelling of fresh-water heads and borehole resistivities observed on the shore. Proceedings MODELCARE 96 Calibration and Reliability in Groundwater Modelling, IAHS Publication 237: 199-208.

Lappin, H.M., Greaves, M.P. \& Slater, J.H., 1985. Degradation of the herbicide mecoprop by a synergistic microbial community. Applied Environmental Microbiology 49: 429-433.

Li, J., Langford, C.H. \& Gamble, D.S., 1996. Atrazine sorption by mineral soil - effects of soil size fractions and temperature. Journal of Agricultural and Food Chemistry 44: 3680-3684.

Loague, K., Abrams, S.N., Davis, S.N., Nguyen, A. \& Stewart, I.T., 1998. A case study simulation of DBCP groundwater contamination in Fresno County, California - 2. Transport in the saturated subsurface. Journal of Contaminant Hydrology 29: 137162.

Maloszewski, P., Zuber, A., Bedbur, E. \& Matthess, G., 2003. Transport of three pesticides in ground water at Twin Lake Test Site, Chalk River, Ontario, Canada. Groundwater 41: 376-386.

Matthess, G., 1994. Die Beschaffenheit des Grundwassers. Gebrüder Borntraeger, Berlin: $499 \mathrm{pp}$.

McDonald, M.G. \& Harbaugh, A.W., 1988. A modular three-dimensional finite-difference ground-water flow model-U.S. Geological Survey, Techniques of Water-Resources Investigations Book 6: 586 pp.

Moreau-Kervévan, C. \& Mouvet, C., 1998. Adsorption and desorption of atrazine, deethylatrazine and hydroxyatrazine by soil components. Journal of Environmental Quality 27: 46-53.

Mouvet, C., Jeannot, R., Rutland, H. \& Maciag, C., 1997. Stability of isoproturon, bentazone, terbuthylazine and alachlor in natural groundwater, surface water and soil water samples stored under laboratory conditions. Chemosphere 35: 1083-1097.

Pestemer, W. \& Nordmeyer, H., 1990. Modelluntersuchungen mit ausgewählten Pflanzenschutzmitteln im Bodenprofil im Hinblick auf die Beurteilung einer Grundwasserbelastung. Mitteilungen Biologischer Bundesanstalt für Land und Forstwirtschaft 259: 1-80. 
Smith, A. \& Hayden, B., 1981. Relative persistence of MCPA, MCPB and mecoprop in Saskatchewan soils, and identification of MCPA in MCPB-treated soils. Weed Research 21: 179-183.

Toräng, L., Nyholm, N. \& Albrechtsen, H., 2003. Shifts in biodegradation kinetics of the herbicides MCPP and 2,4-D at low concentrations in aerobic aquifer materials. Environmental Science and Technology 37: 3095-3103.

Van den Berg, R., Van der Linden, T., Mühlschlegel, J., van Beek, C., Jobson, J., Leistra, M. \& Hoeks J, 1990. Verdunning en omzetting van bestrijdingsmiddelen in grondwater. Bilthoven, Rijksinstituut voor volksgezondheid en milieuhygiëne Rapport nr. 725801002: $64 \mathrm{pp}$.

Van der Linden, A.M.A. \& Boesten, J.J.T.I., 1989. Berekening van de mate van uitspoeling en accumulatie van bestrijdingsmiddelen als functie van hun sorptiecoëfficiënt en omzettingssnelheid in bouwvoormateriaal. Bilthoven, Rijksinstituut voor volksgezondheid en milieuhygiëne Rapport nr. 728800003: $52 \mathrm{pp}$.

Vande Casteele, K., Gaus, I., De Breuck, W. \& Walraevens, K., 2000. Identification and quantification of 77 pesticides in groundwater using solid phase coupled to micro liquid-liquid extraction and reversed phase liquid chromatography. Analytical Chemistry 72: 3093-3101.

Zheng, C., 1990. MT3D: A Modular Three-Dimensional Transport Model for Simulation of Advection, Dispersion and Chemical Reactions of Contaminants in Groundwater Systems. Report to the USEPA: $170 \mathrm{pp}$. 